УДК 656.052.8.629.113

DOI http://dx.doi.org/10.5281/zenodo.3744396

\title{
VARIANTS OF URICACID METABOLISM AND THEIR IMMUNE AND MICROBIOTA ACCOMPANIMENTS IN PATIENTS WITH NEUROENDOCRINE-IMMUNE COMPLEX DYSFUNCTION
}

\author{
Smagliy' V.S., Gozhenko' A.I., Korda² I.V., Badiuk' N.S., Zukow ${ }^{3}$ W., \\ Kovbasnyuk M.M., Popovych ${ }^{1,4}$ I.L. \\ ${ }^{1}$ Ukrainian Scientific Research Institute of Medicine for Transport, Odessa \\ prof.gozhenko@gmail.com; badiuk_ns@ukr.net \\ 2YY Horbachevs'kyi National Medical University, Ternopil', kordai@tdmu.edu.ua \\ ${ }^{3}$ Nicolaus Copernicus University, Torun, Poland zukow@umk.pl \\ ${ }^{4} \mathrm{OO}$ Bohomolets' Institute of Physiology, Kyïv i.popovych@biph.kiev.ua
}

\section{ВАРІАНТИ МЕТАБОЛІЗМУ СЕЧОВОЇ КИСЛОТИ ТА ЇХ ІМУННІ Й МІКРОБІОТНІ ЗВ'ЯЗКИ У ПАЦІЄНТІВ З НЕЙРОЕНДОКРИННО- ІМУННОЮ КОМПЛЕКСНОЮ ДИСФУНКЦІЕЮ}

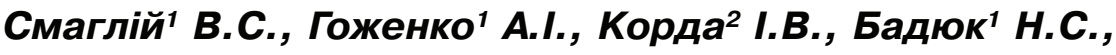 \\ Жуков ${ }^{3}$ В.А., Ковбаснюк М.М., Попович ${ }^{1,4}$ І.Л. \\ 'Український НДІ медицини транспорту, Одеса \\ ${ }^{2}$ Національний медичний університет ім. І. Я. Горбачевського, Тернопіль \\ ${ }^{3}$ Університет Миколи Коперника, Торунь, Польща \\ ${ }^{4}$ /нститут фізіології ім. О. О. Богомольця НАН України, Київ
}

\section{ВАРИАНТЫ МЕТАБОЛИЗМА МОЧЕВОЙ КИСЛОТЫ И ИХ ИММУННЫЕ И МИКРОБИОТНЫЕ СВЯЗИ У ПАЦИЕНТОВ С НЕЙРОЭНДОКРИННО-ИММУННОЙ КОМПЛЕКСНОЙ ДИСФУНКЦИЕЙ}

\author{
Смаглий' В.С., Гоженко1 А.И., Корда ${ }^{2}$ И.В. , Бадюк' Н.С., \\ Жуков ${ }^{3}$ В.А., Ковбаснюк ${ }^{4}$ М.М., Попович ${ }^{1,4}$ И.Л. \\ ${ }^{1}$ Украинский НИИ медицины транспорта, Одесса \\ ${ }^{2}$ Национальный медицинский университет им. И. Я. Горбачевского, \\ Тернополь \\ ${ }^{3}$ Униерситет Николая Коперника, Торунь, Польша \\ ${ }^{4}$ Институт физиологии им. А. А. Богомольца НАН Украины, Киев
}

\section{Summary/Резюме}

Background. Previously, we found a wide range of uric acid exchange parameters and functional relationships of uricemia and uricosuria with the parameters of immunity in healthy rats analyzed. We continued our research along the same lines in the clinical observation of patients, who came to the Truskavets' spa for the rehabilitation treatment. Relationships between uricemia and uricosuria, on the one hand, and immunity and microbiota parameters, on the other hand, have been identified. The purpose of this study is to further explore these relationships using the cluster and discriminant analyses. Material and Methods. The object of observation were 34 men and 10 women aged 24-70 years old, who came to the Truskavets' spa for the rehabilitation treatment of chronic pyelonephritis combined with cholecystitis in remission. The serum and daily urine levels of the uric acid by uricase method 
were determined. Immune status evaluated on a set of I and II levels recommended by the WHO. The condition of microbiota is evaluated on the results of sowing of feces and urine. Results. Cluster analysis revealed 4 variants of uric acid metabolism by deviating uricosuria and uricemia from the norm in Z-scores. In 34\% of individuals, moderate hypouricosuria ($0,97 \pm 0,11 \mathrm{Z})$ is combined with a lower borderline uricemia $(-0,53 \pm 0,20 \mathrm{Z})$. In $25 \%$ of patients, lower-border uricemia $(-0,70 \pm 0,22 \mathrm{Z})$ is accompanied by marked hyperuricosuria $(+3,87 \pm 0,25 \mathrm{Z})$. In $24 \%$ of people, moderately elevated uricosuria $(+1,26 \pm 0,14 \mathrm{Z})$ is combined with completely normal uricemia $(+0,09 \pm 0,16 \mathrm{Z})$. Finally, in $17 \%$, a similar level of uricosuria $(+1,17 \pm 0,19 \mathrm{Z})$ is combined with marked hypouricemia $(-1,89 \pm 0,14 \mathrm{Z})$. Discriminant analysis revealed 12 parameters of immunity and 5 parameters of microbiota, by which the clusters of uric acid metabolism are identified with $94,3 \% \%$ accuracy.

Conclusion. Endogenous uric acid has a modulating overall beneficial effect on a number of immune and microbiota parameters in both healthy rats and people with neuroendocrine-immune complex dysfunction on background of chronic inflammatory diseases.

Keywords: Uricemia, Uricosuria, Immunity, Microbiota, Relationships, Humans.

Передумови. Раніше ми виявили широкий діапазон параметрів обміну сечової кислоти та проаналізували функціональні зв'язки урикемії і урикозурії з параметрами імунітету у здорових щурів. Ми продовжували наше дослідження за тими ж напрямками у клінічному спостереженні за пацієнтами, які прибували на курорт Трускавець на реабілітаційне лікування. Було виявлено зв'язки між урикемією та урикозурією, з одного боку, і імунітетом та параметрами мікробіоти, з іншого. Метою цього дослідження $є$ подальше вивчення цих зв'язків за допомогою кластерного та дискримінантного аналізів. Матеріал та методи. Об'єктом спостереження були 34 чоловіки та 10 жінок у віці 24-70 років, які прибули на курорт Трускавець на реабілітаційне лікування хронічного пієлонефриту, поєднаного з холециститом, у стадії ремісії. Визначали рівень сечової кислоти в сироватці та добовій сечі уриказним методом. Імунний статус оцінювали за набором тестів I та II рівнів, рекомендованих ВООЗ. Стан мікробіоти оцінено за результатами посіву калу та сечі уніфікованими методами. Результати. Кластерний аналіз виявив 4 варіанти метаболізму сечової кислоти за відхиленнями урикозурії та урикемії від норми у Z-одиницях. У $34 \%$ осіб помірна гіпоурикозурія $(-0,97 \pm 0,11$ Z) поєднується з нижньопограничною урикемією $(-0,53 \pm 0,20$ Z). У 25\% пацієнтів нижньопогранична урикемія $(-0,70 \pm 0,22$ Z) супроводжується вираженою гіперурикозурією $(+3,87 \pm 0,25$ Z). У $24 \%$ людей помірно підвищена урикозурія $(+1,26 \pm 0,14$ Z) поєднується з цілком нормальною урикемією (+0,09 0,16 Z). Нарешті, у $17 \%$ осіб аналогічний рівень урикозурії $(+1,17 \pm 0,19$ Z) поєднується із вираженою гіпоурикемією $(-1,89 \pm 0,14$ Z). Дискримінантний аналіз виявив 12 параметрів імунітету та 5 параметрів мікробіоти, за сукупністю яких кластери метаболізму сечової кислоти ідентифікуються 3 точністю 94,3\%. Висновок. Ендогенна сечова кислота чинить модулюючий загалом сприятливий вплив на ряд параметрів імунітету та мікробіоти як у здорових щурів, так і у людей з дисфункцією нейроендокринно-імунного комплексу на тлі хронічних запальних захворювань.

Ключові слова: урикемія, урикозурія, імунітет, мікробіота, кореляції, люди.

Предпосылки. Ранее мы выявили широкий диапазон параметров обмена мочевой кислоты и проанализировали функциональные связи урикемии и урикозурии с параметрами иммунитета у здоровых крыс. Мы продолжили наши исследования в том 
же направлении в клинических исследованиях за пациентами, которые прибывали на курорт Трускавец для реабилитационного лечения. Были выявлены связи между урикемией и урикозурией, с одной стороны, и иммунитетом и параметрами микробиоты, с другой. Целью исследования было дальнейшее изучение этих связей с использованием кластерного и дискриминантного анализов. Материал и методы. Объектом наблюдения были 34 мужчины и 10 женщин в возрасте 24-70 лет, которые прибыли на курорт Трускавец для реабилитационного лечения хронического пиелонефрита в сочетании с холециститом, в стадии ремиссии. Определили уровень мочевой кислоты в сиворотке и суточной моче уриказным методом. Иммунный статус оценивали наборами тестов I и II уровней, рекомендованных ВОЗ. Состояние микробиоты оценили по результатам посева кала и мочи унифицированными методами. Результаты. По результатам кластерного анализа выявили 4 варианта метаболизма мочевой кислоты по отклонениям урикозурии и урикемии от нормы в Z-единицах. У $34 \%$ пациентов умеренная гипоурикозурия $(-0,97 \pm 0,11 Z)$ сочетается с нижнепограничной урикемией $(-0,53 \pm 0,20$ Z). У $25 \%$ пациентов нижнепограничная урикемия $(-0,70 \pm 0,22$ Z) сопро-

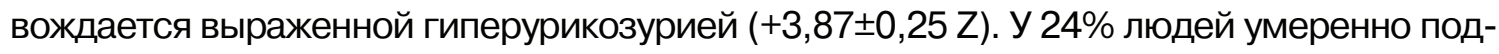
вышена урикозурия $(+1,26 \pm 0,14 \mathrm{Z})$ сочетается с вполне нормальной урикемией $(+0,09 \pm 0,16$ Z). Наконец, у 17\% пациентов аналогичный уровень урикозурии $(+1,17 \pm 0,19$ Z) сочетается с выраженной гипоурикемией $(-1,89 \pm 0,14$ Z). Дискриминантный анализ выявил 12 параметров иммунитета и 5 параметров микробиоты, по совокупности которых кластеры метаболизма мочевой кислоты идентифицируются с точностью 94,3\%. Вывод. Эндогенная мочевая кислота оказывает модулирующее в целом благоприятное влияние на ряд параметров иммунитета и микробиоты как у здоровых крыс, так и у людей с дисфункцией нейроэндокринно-иммунного комплекса на фоне хронических воспалительных заболеваний.

Ключевые слова: урикемия, урикозурия, иммунитет, микробиота, корреляции, люди.

\section{Introduction}

Previously, we found a wide range of uric acid metabolism parameters grouped into four clusters [5] and functional relationships of uricemia and uricosuria with the parameters of immunity in female rats analyzed $[6,7]$. We continued our research along the same lines in the clinical observation of patients, who came to the Truskavets' spa for the rehabilitation treatment. The canonical correlation analysis revealed that raw uricemia determines by $28 \%$ nine parameters of immunity (relative blood content of pan-lymphocytes and their $\mathrm{CD}^{+}-$, CD56+-, 0-populations, relative content of polymorphonuclear neutrophils, intensity and completeness of their phagocytosis Staph. aureus and their bactericidal capacity, saliva content of $\lg G$ ) as well as bacteriuria and content in $\mathrm{E}$. coli feces. Uricemia normalized by sex and age, determines by $25 \%$ another constellation of immunity parameters (relative CD8 ${ }^{+} \mathrm{T}$-lymphocytes content, CIC, E. coli phagocytosis intensity and completeness, Staph. aureus phagocytosis activity and completeness) as well as content in $\mathrm{E}$. coli feces with impaired enzymatic activity and Klebsiela\&Proteus. Instead, uricosuria determines only four parameters of immunity and only by $11,5 \%$ [8].

The purpose of this study is to further explore the relationship between uric acid metabolism and immunity parameters, as well as microbiota parameters, which in turn are closely linked to immunity [23].

\section{Material and methods}

The object of observation were 34 men and 10 women aged $24-70$ years old, with neuroendocrine-immune complex dysfunction on the background of chronic pyelonephritis combined with cholecystitis in remission, documented in a previous study 
$[18,19]$. The survey was conducted twice, before and after ten-day balneotherapy (drinking Naftussya bioactive water three times a day, ozokerite applications, mineral baths every other day) [10].

The serum and daily urine levels of the Uric acid by uricase method were determined. The analyzes were carried out according to the instructions described in the manual [4]. The analyzers "Pointe-180" ("Scientific", USA) were used with appropriate sets.

In portion of capillary blood we counted up Leukocytogram (LCG) (Eosinophils, Stub and Segmentonucleary Neutrophils, Lymphocytes and Monocytes) and calculated two variants of Adaptation Index as well as two variants of Strain Index by IL Popovych $[2,16]$.

Strain Index-1 $=\left[(\mathrm{Eo} / 3,5-1)^{2}+(\mathrm{SN} / 3,5-1)^{2}\right.$ $\left.+(\text { Mon } / 5,5-1)^{2}+(\text { Leu } / 6-1)^{2}\right] / 4$

Strain Index-2 $=\left[(\mathrm{Eo} / 2,75-1)^{2}+(\mathrm{SN} / 4,25-\right.$ $\left.1)^{2}+(\text { Mon/6-1 })^{2}+(\text { Leu/5-1 })^{2}\right] / 4$

Immune status evaluated on a set of I and II levels recommended by the WHO as described in the manuals $[11,14]$. For phenotyping subpopulations of lymphocytes used the methods of rosette formation with sheep erythrocytes on which adsorbed monoclonal antibodies against receptors CD3, CD4, CD8, CD22 and CD56 from company "Granum" (Kharkiv) with visualization under light microscope with immersion system. Subpopulation of $T$ cells with receptors high affinity determined by test of "active" rosette formation. The state of humoral immunity judged by the concentration in serum circulating immune complexes (by polyethylene glycol precipitation method) and Immunoglobulins classes M, G, A (ELISA analyser "Immunochem", USA). In addition, the saliva level of secretory $\lg A, \lg A$ and $\lg G$ was determined as well as lysozime (by bacteriolysis of Micrococcus lysodeikticus).

We calculated also the Entropy (h) of Immunocytogram (ICG) and Leukocytogram (LCG) using formulas [17,20,24], adapted from classical CE Shannon's formula [22]:
$\mathrm{hICG}=-\left[\mathrm{CD} 4 \cdot \log _{2} \mathrm{CD} 4+\mathrm{CD} 8 \cdot \log _{2} \mathrm{CD} 8+\right.$ $\left.\mathrm{CD} 22 \cdot \log _{2} \mathrm{CD} 22+\mathrm{CD} 56 \cdot \log _{2} \mathrm{CD} 56\right] / \log _{2}$ 4

$\mathrm{hLCG}=-\left[\mathrm{L} \cdot \log _{2} \mathrm{~L}+\mathrm{M} \cdot \log _{2} \mathrm{M}+\mathrm{E} \cdot \log _{2} \mathrm{E}+\right.$ SNN $\cdot \log _{2}$ SNN + StubN $\cdot \log _{2}$ StubN] $/ \log _{2} 5$

Parameters of phagocytic function of neutrophils estimated as described by SD Douglas and PG Quie [3] with moderately modification by MM Kovbasnyuk $[13,21]$. The objects of phagocytosis served daily cultures of Staphylococcus aureus (ATCC N 25423 F49) as typical specimen for Grampositive Bacteria and Escherichia coli (O55 K59) as typical representative of Gram-negative Bacteria Both cultures obtained from Laboratory of Hydro-Geological RegimeOperational Station JSC "Truskavets'kurort". Take into account the following parameters of Phagocytosis: activity (percentage of neutrophils, in which found microbes - Hamburger's Phagocytic Index Phl), intensity (number of microbes absorbed one phagocytes - Microbial Count MC or Right's Index) and completeness (percentage of dead microbes - Killing Index KI). On the basis of the recorded partial parameters of Phagocytosis, taking into account the Neutrophils $(\mathrm{N})$ content of $1 \mathrm{~L}$ blood, we calculated the integral parameter - Bactericidal Capacity of Neutrophils (BCCN) by the formula [10]:

$\operatorname{BCCN}\left(10^{9}\right.$ Bact $\left./ \mathrm{L}\right)=\mathrm{N}\left(10^{9} / \mathrm{L}\right) \cdot \mathrm{Phl}(\%) \cdot \mathrm{MC}$ (Bact/Phag) $\cdot \mathrm{KI}(\%) \cdot 10^{-4}$

In addition, the blood level of cytokines IL-1, IL- 6 and TNF- 6 was determined (by the ELISA with the use of analyzer "RT-2100C" and corresponding sets of reagents from "Diactone", France). The condition of Microbiota is evaluated on the results of sowing of feces and urine.

Norms are borrowed from the Instructions and Database of the Truskavets' Scientific School of Balneology.

Results processed by methods of cluster [1] and discriminant [12] analyses, using the software package "Statistica 5.5".

\section{Results and Discussion}

Preliminary examination revealed a 
wide dispersion of both the concentration of Uric Acid in serum and its excretion in the urine (normalized by sex and age [8]), as was the case in healthy female rats [5]. This why the cluster is labeled S \pm E-. In $25 \%$ of patients (18 men and 4 women), lower-border uricemia is accompanied by marked hyperuricosuria (S-E2+ cluster). In $24 \%$ of peo-

Table 1 ple $(16$ men and 5 women), moderately elevated uricosuria is associated with completely normal uricemia ( $\mathrm{S} \pm \mathrm{E}+$ cluster). Finally, in $17 \%$ (14

Table 2

Members of Clusters and Distances from Respective Cluster Center

\begin{tabular}{|c|c|c|c|c|c|c|c|c|c|c|c|c|c|c|c|c|}
\hline \multicolumn{17}{|c|}{ Cluster Number 1 contains 21 cases } \\
\hline & $\begin{array}{l}\text { Case } \\
\text { No. }\end{array}$ & $\begin{array}{l}\text { Case } \\
\text { No. }\end{array}$ & $\begin{array}{l}\text { Case } \\
\text { No. }\end{array}$ & $\begin{array}{l}\text { Case } \\
\text { No. }\end{array}$ & $\begin{array}{l}\text { Case } \\
\text { No. }\end{array}$ & $\begin{array}{l}\text { Case } \\
\text { No. }\end{array}$ & $\begin{array}{l}\text { Case } \\
\text { No. }\end{array}$ & $\begin{array}{l}\text { Case } \\
\text { No. }\end{array}$ & $\begin{array}{l}\text { Case } \\
\text { No. }\end{array}$ & $\begin{array}{l}\text { Case } \\
\text { No. }\end{array}$ & $\begin{array}{l}\text { Case } \\
\text { No. }\end{array}$ & \begin{tabular}{|l} 
Case \\
No. \\
\end{tabular} & $\begin{array}{l}\text { Case } \\
\text { No. }\end{array}$ & \begin{tabular}{|l} 
Case \\
No. \\
\end{tabular} & $\begin{array}{l}\text { Case } \\
\text { No. }\end{array}$ & $\begin{array}{l}\text { Case } \\
\text { No. }\end{array}$ \\
\hline & C_22 & C_26 & C_29 & C_31 & C_34 & C_36 & C_40 & C_50 & C_51 & C_54 & C_58 & C_59 & C_73 & C_78 & C_79 & C_80 \\
\hline Distance & 0,58 & 0,81 & 1,18 & 0,97 & 0,22 & 0,38 & 0,57 & 0,31 & 0,8 & 0,79 & 0,51 & 0,76 & 0,91 & 0,69 & 0,52 & 0,81 \\
\hline & $\begin{array}{l}\text { Case } \\
\text { No. }\end{array}$ & $\begin{array}{l}\text { Case } \\
\text { No. }\end{array}$ & $\begin{array}{l}\text { Case } \\
\text { No. }\end{array}$ & $\begin{array}{l}\text { Case } \\
\text { No. }\end{array}$ & $\begin{array}{l}\text { Case } \\
\text { No. }\end{array}$ & & & & & & & & & & & \\
\hline & C_7 & C_10 & C_13 & C_15 & C_17 & & & & & & & & & & & \\
\hline Distance & 0,52 & 0,78 & 0,46 & 0,4 & 0,49 & & & & & & & & & & & \\
\hline
\end{tabular}

\begin{tabular}{|l|l|l|l|l|l|l|l|l|l|l|l|l|l|l|l|}
\hline & \multicolumn{10}{c|}{2 contains 15 cases } \\
& $\begin{array}{l}\text { Case } \\
\text { No. }\end{array}$ & $\begin{array}{l}\text { Case } \\
\text { No. }\end{array}$ & $\begin{array}{l}\text { Case } \\
\text { No. }\end{array}$ & $\begin{array}{l}\text { Case } \\
\text { No. }\end{array}$ & $\begin{array}{l}\text { Case } \\
\text { No. }\end{array}$ & $\begin{array}{l}\text { Case } \\
\text { No. }\end{array}$ & $\begin{array}{l}\text { No. } \\
\text { No. }\end{array}$ & $\begin{array}{l}\text { Case } \\
\text { No. }\end{array}$ & $\begin{array}{l}\text { Case } \\
\text { No. }\end{array}$ & $\begin{array}{l}\text { Case } \\
\text { No. }\end{array}$ & $\begin{array}{l}\text { Case } \\
\text { No. }\end{array}$ & $\begin{array}{l}\text { Case } \\
\text { No. }\end{array}$ & $\begin{array}{l}\text { Case } \\
\text { No. }\end{array}$ & $\begin{array}{l}\text { Case } \\
\text { No. }\end{array}$ \\
\hline Distance & C_2 & C_3 & C_21 & C_24 & C_27 & C_30 & C_39 & C_43 & C_46 & C_47 & C_56 & C_65 & C_72 & C_85 & C_87 \\
\hline & 0,53 & 0,32 & 1,04 & 0,66 & 0,48 & 0,95 & 0,68 & 0,64 & 0,51 & 0,31 & 0,69 & 0,49 & 0,73 & 0,4 & 0,64 \\
\hline
\end{tabular}

Cluster Number 3 contains 30 cases

\begin{tabular}{|c|c|c|c|c|c|c|c|c|c|c|c|c|c|c|c|}
\hline & $\begin{array}{l}\text { Case } \\
\text { No. }\end{array}$ & $\begin{array}{l}\text { Case } \\
\text { No. }\end{array}$ & $\begin{array}{l}\text { Case } \\
\text { No. } \\
\end{array}$ & \begin{tabular}{|l|} 
Case \\
No. \\
\end{tabular} & $\begin{array}{l}\text { Case } \\
\text { No. } \\
\end{array}$ & $\begin{array}{l}\text { Case } \\
\text { No. } \\
\end{array}$ & $\begin{array}{l}\text { Case } \\
\text { No. }\end{array}$ & \begin{tabular}{|l|} 
Case \\
No. \\
\end{tabular} & $\begin{array}{l}\text { Case } \\
\text { No. }\end{array}$ & $\begin{array}{l}\text { Case } \\
\text { No. }\end{array}$ & $\begin{array}{l}\text { Case } \\
\text { No. } \\
\end{array}$ & $\begin{array}{l}\text { Case } \\
\text { No. } \\
\end{array}$ & $\begin{array}{l}\text { Case } \\
\text { No. }\end{array}$ & \begin{tabular}{|l|} 
Case \\
No. \\
\end{tabular} & \begin{tabular}{|l} 
Case \\
No.
\end{tabular} \\
\hline & $\begin{array}{l}\text { C } 52 \\
\text {. }\end{array}$ & C 53 & C 60 & C 62 & C 63 & C 64 & C 66 & C 74 & C 75 & C 76 & C 77 & C 81 & C 82 & C 83 & C 84 \\
\hline Dis & 0,67 & 0,86 & 0,42 & 0,52 & 0,67 & 0,64 & 0,33 & 0,97 & $\overline{0,78}$ & 0,62 & 0,41 & 0,92 & 0,69 & 0,49 & 1,11 \\
\hline & $\begin{array}{l}\text { Case } \\
\text { No. }\end{array}$ & $\begin{array}{l}\text { Case } \\
\text { No. }\end{array}$ & $\begin{array}{l}\text { Case } \\
\text { No. }\end{array}$ & \begin{tabular}{|l} 
Case \\
No.
\end{tabular} & $\begin{array}{l}\text { Case } \\
\text { No. }\end{array}$ & $\begin{array}{l}\text { Case } \\
\text { No. }\end{array}$ & $\begin{array}{l}\text { Case } \\
\text { No. }\end{array}$ & $\begin{array}{l}\text { Case } \\
\text { No. }\end{array}$ & $\begin{array}{l}\text { Case } \\
\text { No. }\end{array}$ & $\begin{array}{l}\text { Case } \\
\text { No. }\end{array}$ & $\begin{array}{l}\text { Case } \\
\text { No. }\end{array}$ & $\begin{array}{l}\text { Case } \\
\text { No. }\end{array}$ & $\begin{array}{l}\text { Case } \\
\text { No. }\end{array}$ & $\begin{array}{l}\text { Case } \\
\text { No. }\end{array}$ & $\begin{array}{l}\text { Case } \\
\text { No. }\end{array}$ \\
\hline & C_4 & C_6 & C_8 & C_9 & C_12 & C_16 & C_18 & C_19 & C_23 & C_32 & C_33 & C_38 & C_41 & C_42 & C_48 \\
\hline Distance & 1,15 & 0,61 & 0,78 & 2,19 & 0,38 & 1,3 & $\overline{0,9}$ & 0,74 & 0,67 & 0,57 & 0,08 & 1,01 & 0,91 & 0,81 & 1, \\
\hline
\end{tabular}

\begin{tabular}{|r|r|r|r|r|r|r|r|r|r|r|}
\hline & 1,15 & 0,61 & 0,78 & 2,19 & 0,38 & 1,3 & 0,9 & 0,74 & 0,67 & 0,5 \\
\hline
\end{tabular}

\begin{tabular}{|l|l|l|l|l|l|l|l|l|l|l|l|l|l|l|l|l|}
\hline & Case & Case & Case & Case & $\begin{array}{l}\text { Case } \\
\text { No. }\end{array}$ & Case & Case & $\begin{array}{l}\text { Case } \\
\text { No. }\end{array}$ & $\begin{array}{l}\text { Case } \\
\text { No. }\end{array}$ & $\begin{array}{l}\text { Case } \\
\text { No. }\end{array}$ & $\begin{array}{l}\text { Case } \\
\text { No. }\end{array}$ & $\begin{array}{l}\text { Case } \\
\text { No. }\end{array}$ & $\begin{array}{l}\text { Case } \\
\text { No. }\end{array}$ & $\begin{array}{l}\text { Case } \\
\text { No. }\end{array}$ & $\begin{array}{l}\text { Case } \\
\text { No. }\end{array}$ \\
\hline & C_1 & C_5 & C_11 & C_14 & C_20 & C_25 & C_28 & C_35 & C_37 & C_44 & C_45 & C_49 & C_55 & C_57 & C_61 \\
\hline Distance & 0,92 & 0,88 & 0,75 & 0,61 & 0,92 & 0,73 & 0,72 & 0,6 & 1,03 & 2,15 & 1,17 & 0,33 & 0,8 & 1,5 & 2,02 \\
\hline
\end{tabular}

\begin{tabular}{|l|r|r|r|r|r|r|r|}
\hline & Case & $\begin{array}{l}\text { Case } \\
\text { No. }\end{array}$ & $\begin{array}{l}\text { Case } \\
\text { No. }\end{array}$ & $\begin{array}{l}\text { Case } \\
\text { No. }\end{array}$ & $\begin{array}{l}\text { Case } \\
\text { No. }\end{array}$ & $\begin{array}{l}\text { Case } \\
\text { No. }\end{array}$ & $\begin{array}{l}\text { Case } \\
\text { No. }\end{array}$ \\
\hline & C_67 & C_68 & C_69 & C_70 & C_71 & C_86 & C_88 \\
\hline Distance & 0,85 & 0,58 & 0,56 & 0,81 & 0,65 & 0,88 & 1,77 \\
\hline
\end{tabular}

prompted us to re-apply cluster analysis (kmean clustering method [1]).

As a result, four groups of persons were created, significantly different from each other in parameters of Uric Acid exchange (Table 1), while the differences between the members of each group were much smaller (Table 2).

The location of the members of the four clusters on the plane of uricemia and uricosuria is visualized in Fig. 1.

In $34 \%$ of individuals (20 males and 10 females), moderate hypouricosuria is combined with lower-grade uricemia, which is

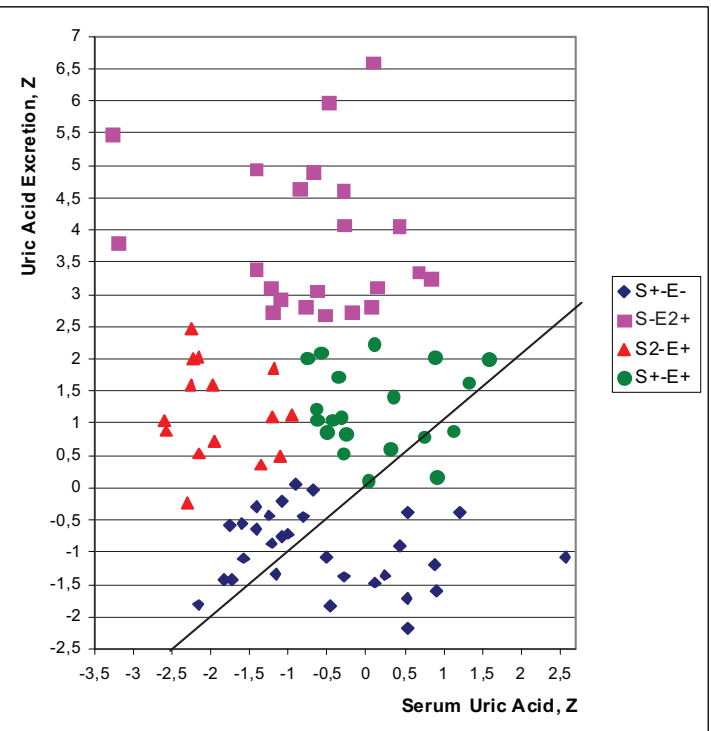

Fig. 1. Normalized levels (Z-scores) of uricemia (X-line) and uricosuria ( $\mathrm{Y}$-line) in patients of different clusters 
Table 3 men and 1 woman), a

Discriminant Function Analysis Summary for Variables of Uric Acid Exchange, Immunity and Microbiota

Step 21, $N$ of vars in model: 19; Grouping: 4 grps; Wilks' $\Lambda$ : 0,00478; approx. $F_{(57)}=17,3 ; p<10^{-6}$

\begin{tabular}{|c|c|c|c|c|c|c|c|c|c|c|}
\hline \multirow[t]{2}{*}{$\begin{array}{l}\text { Variables } \\
\text { currently in the model }\end{array}$} & \multicolumn{4}{|c|}{$\begin{array}{l}\text { Clusters of Uric Acid } \\
\text { Exchange (n) }\end{array}$} & \multicolumn{5}{|c|}{ Parameters of Wilks' Statistics } & \multirow{2}{*}{\begin{tabular}{|l} 
\\
Norm \\
Cv/ $/ \boldsymbol{\sigma}$ \\
$(30)$
\end{tabular}} \\
\hline & $\begin{array}{l}\mathrm{S} \pm \mathrm{E}-\mathrm{III} \\
(30)\end{array}$ & $\begin{array}{l}\text { S2-E+ } \\
\text { II } \\
\text { (15) }\end{array}$ & $\begin{array}{l}\mathrm{S} \pm \mathrm{E}+ \\
\mathrm{I} \\
(21)\end{array}$ & $\begin{array}{l}\text { S-E2+ } \\
\text { IV } \\
(22)\end{array}$ & $\begin{array}{l}\text { Wilks } \\
\wedge\end{array}$ & $\begin{array}{l}\text { Par- } \\
\text { tial } \\
\Lambda\end{array}$ & $\begin{array}{l}\text { F-re- } \\
\text { move } \\
(3,7)\end{array}$ & \begin{tabular}{|l|}
$\mathrm{p}-$ \\
le-vel
\end{tabular} & $\begin{array}{l}\text { Toler } \\
\text { an-cy }\end{array}$ & \\
\hline $\begin{array}{l}\text { Serum Uric Acid, } \mathrm{mM} / \mathrm{L} \\
\mathrm{Z}\end{array}$ & $\begin{array}{l}0,322 \\
-0,53\end{array}$ & $\begin{array}{l}0,249 \\
-1,89\end{array}$ & $\begin{array}{l}0,371 \\
+0,09\end{array}$ & $\begin{array}{l}0,316 \\
-0,70\end{array}$ & 0,0063 & 0,758 & 7 & $10^{-3}$ & 0,658 & $\begin{array}{l}0,365 \\
0,116\end{array}$ \\
\hline $\begin{array}{l}\text { Uric Acid Excr, mM/24 } \\
\text { h } \\
Z\end{array}$ & $\begin{array}{l}2,27 \\
-0,97\end{array}$ & $\begin{array}{r}3,88 \\
+1,17\end{array}$ & $\begin{array}{c}3,94 \\
+1,26\end{array}$ & $\begin{array}{c}5,94 \\
+3,87\end{array}$ & 0,039 & 0,123 & 157 & $10^{-6}$ & 0,647 & $\begin{array}{l}3,00 \\
0,250\end{array}$ \\
\hline $\begin{array}{l}\text { Popovych's Strain } \\
\text { Index-1, points }\end{array}$ & 0,13 & 0,16 & 0,25 & 0,13 & 0,005 & 0,953 & 1,1 & 0,362 & 0,754 & $\begin{array}{l}0,067 \\
0,722 \\
\end{array}$ \\
\hline $\begin{array}{l}\text { Killing Index vs Staph. } \\
\text { aureus, } \%\end{array}$ & 47,9 & 47,9 & 53,0 & 49,5 & 0,0049 & 0,98 & 0,4 & 0,72 & 0,312 & $\begin{array}{r}58,9 \\
0,142 \\
\end{array}$ \\
\hline $\begin{array}{l}\text { Lysozime Saliva, } \\
\text { mg/L }\end{array}$ & 171 & 171 & 172 & 167 & 0,0059 & 0,804 & 5,4 & 0,002 & 0,249 & $\begin{array}{c}180 \\
0,168 \\
\end{array}$ \\
\hline $\begin{array}{l}\text { Phagocytose Index vs } \\
\text { Staph. aureus, \% }\end{array}$ & 98,96 & 99,00 & 99,00 & 98,54 & 0,0057 & 0,843 & 4,1 & 0,01 & 0,318 & $\begin{array}{r}98,3 \\
0,018 \\
\end{array}$ \\
\hline $\begin{array}{l}\text { Pan-Lymphocytes } \\
\text { of Blood, \% } \\
\end{array}$ & 33,9 & 35,8 & 31,7 & 34,6 & 0,0055 & 0,868 & 3,3 & 0,025 & 0,306 & $\begin{array}{r}32,0 \\
0,174 \\
\end{array}$ \\
\hline $\begin{array}{l}\text { Phagocytose Index } \\
\text { vs E. coli, \% }\end{array}$ & 99,43 & 98,80 & 99,13 & 98,40 & 0,0057 & 0,845 & 4 & 0,011 & 0,295 & $\begin{array}{r}98,3 \\
0,012 \\
\end{array}$ \\
\hline $\begin{array}{l}\text { Erythrocyturia, } \\
\text { points }\end{array}$ & 0,12 & 0,08 & 0,07 & 0,12 & 0,0051 & 0,935 & 1,5 & 0,212 & 0,662 & $\begin{array}{c}0 \\
0,10\end{array}$ \\
\hline $\begin{array}{l}\text { IgA Saliva, } \\
\mathrm{mg} / \mathrm{L}\end{array}$ & 144 & 142 & 135 & 118 & 0,0054 & 0,887 & 2,8 & 0,047 & 0,215 & $\begin{array}{c}415 \\
0,241\end{array}$ \\
\hline $\begin{array}{l}\text { Bifidobacterium } \\
\text { faeces, lg CFU/g }\end{array}$ & 5,66 & 5,40 & 5,49 & 5,74 & 0,0055 & 0,867 & 3,4 & 0,023 & 0,016 & $\begin{array}{c}6,94 \\
0,011 \\
\end{array}$ \\
\hline $\begin{array}{l}\text { Lactobacillus faeces, } \\
\text { Ig CFU/g }\end{array}$ & 6,38 & 6,14 & 6,31 & 6,48 & 0,0053 & 0,902 & 2,4 & 0,078 & 0,015 & $\begin{array}{c}8,10 \\
0,015 \\
\end{array}$ \\
\hline $\begin{array}{l}\text { Leukocyturia, } \\
\mathrm{Ig} / \mathrm{mL}\end{array}$ & 3,44 & 3,19 & 3,26 & 3,44 & 0,0056 & 0,855 & 3,7 & 0,015 & 0,237 & $\begin{array}{c}3,00 \\
0,070\end{array}$ \\
\hline $\begin{array}{l}\lg G \text { Serum, } \\
\text { g/L }\end{array}$ & 15,6 & 14,5 & 15,1 & 14,4 & 0,0053 & 0,911 & 2,2 & 0,101 & 0,694 & $\begin{array}{l}12,75 \\
0,206\end{array}$ \\
\hline $\begin{array}{l}\text { Bacteriuria, } \\
\text { points }\end{array}$ & 0,27 & 0,43 & 0,22 & 0,28 & 0,0054 & 0,881 & 3 & 0,037 & 0,243 & $\begin{array}{c}0 \\
0,24\end{array}$ \\
\hline $\begin{array}{l}\text { Bactericidity vs Staph. } \\
\text { aureus, } 10^{9} \mathrm{Bacteria/L}\end{array}$ & 94,5 & 90,6 & 103,0 & 93,8 & 0,0055 & 0,877 & 3,1 & 0,034 & 0,233 & $\begin{array}{l}105,7 \\
0,100 \\
\end{array}$ \\
\hline $\begin{array}{l}\text { Entropy of } \\
\text { Immunocytogram }\end{array}$ & 0,956 & 0,964 & 0,967 & 0,967 & 0,0052 & 0,927 & 1,7 & 0,171 & 0,459 & 0,960 \\
\hline $\begin{array}{l}\text { Interleukin-6, } \\
\text { ng/L }\end{array}$ & 5,49 & 5,27 & 5,20 & 5,44 & 0,0051 & 0,929 & 1,7 & 0,182 & 0,202 & $\begin{array}{l}4,25 \\
0,324\end{array}$ \\
\hline $\begin{array}{l}\text { Microbial Count vs E. } \\
\text { coli, } \\
\text { Bacteria/Phagocyte }\end{array}$ & 64,6 & 62,8 & 65,3 & 63,5 & 0,0051 & 0,938 & 1,5 & 0,233 & 0,32 & $\begin{array}{l}54,7 \\
0,194\end{array}$ \\
\hline
\end{tabular}

Note. For some variables instead Cv is SD

Variables of Leukocytogram and Phagocytosis, currently not in the model

\begin{tabular}{|c|c|c|c|c|c|c|c|c|c|c|}
\hline \multirow[b]{2}{*}{ Variables } & \multicolumn{4}{|c|}{$\begin{array}{l}\text { Clusters of Uric Acid } \\
\text { Exchange (n) }\end{array}$} & \multicolumn{5}{|c|}{ Parameters of Wilks' Statistics } & \multirow[b]{2}{*}{$\begin{array}{l}\text { Norm } \\
\text { Cv/o } \\
(30)\end{array}$} \\
\hline & $\begin{array}{l}\mathrm{S} \pm \mathrm{E}-\mathrm{III} \\
(30)\end{array}$ & $\begin{array}{l}\text { S2-E+ } \\
\text { II } \\
(15)\end{array}$ & $\begin{array}{l}\mathrm{S} \pm \mathrm{E}+ \\
(21)\end{array}$ & $\begin{array}{l}\text { S-E2+ } \\
\text { IV } \\
(22)\end{array}$ & $\begin{array}{l}\text { Wilks } \\
\wedge\end{array}$ & $\begin{array}{l}\text { Par- } \\
\text { tial } \\
h\end{array}$ & $\begin{array}{l}\text { F-re- } \\
\text { move } \\
(3,7)\end{array}$ & $\begin{array}{l}\text { p- } \\
\text { le-vel }\end{array}$ & $\begin{array}{l}\text { Toler } \\
\text { an-cy }\end{array}$ & \\
\hline $\begin{array}{l}\text { Leukocytes of Blood, } \\
10^{9} / \mathrm{L}\end{array}$ & 5,67 & 5,48 & 5,55 & 5,91 & 0,0048 & 0,993 & 0,14 & 0,93 & 0,257 & $\begin{array}{c}5,00 \\
0,100\end{array}$ \\
\hline $\begin{array}{l}\text { Polymorphonucleary } \\
\text { Neutrophiles of Blood, } \\
\%\end{array}$ & 54,6 & 52,7 & 55,8 & 53,2 & 0,0048 & 0,995 & 0,1 & 0,96 & 0,073 & $\begin{array}{c}55,0 \\
0,100\end{array}$ \\
\hline $\begin{array}{l}\text { Stubnucleary } \\
\text { Neutrophiles of Blood, } \\
\% \\
\end{array}$ & 2,78 & 2,56 & 2,54 & 2,69 & 0,0047 & 0,987 & 0,29 & 0,83 & 0,469 & $\begin{array}{c}4,25 \\
0,147\end{array}$ \\
\hline $\begin{array}{l}\text { Eosinophiles } \\
\text { of Blood, \% } \\
\end{array}$ & 3,30 & 2,97 & 3,80 & 3,25 & 0,0046 & 0,972 & 0,63 & 0,6 & 0,624 & \begin{tabular}{|l|}
2,75 \\
0,318 \\
\end{tabular} \\
\hline $\begin{array}{l}\text { Monocytes of Blood, } \\
\%\end{array}$ & 5,40 & 6,00 & 6,18 & 6,32 & 0,0047 & 0,99 & 0,23 & 0,88 & 0,689 & $\begin{array}{c}6,0 \\
0,083 \\
\end{array}$ \\
\hline $\begin{array}{l}\text { Microbial Count vs } \\
\text { Staph. aur, } \\
\text { Bact/Phagoc. }\end{array}$ & 62,0 & 64,0 & 63,1 & 60,7 & 0,0048 & 0,994 & 0,14 & 0,94 & 0,275 & $\begin{array}{c}61,6 \\
0,160\end{array}$ \\
\hline $\begin{array}{l}\text { Killing Index } \\
\text { vs E. coli, } \% \\
\end{array}$ & 45,9 & 44,0 & 51,0 & 48,8 & 0,0048 & 0,996 & 0,09 & 0,96 & 0,114 & $\begin{array}{c}62,0 \\
0,156 \\
\end{array}$ \\
\hline $\begin{array}{l}\text { Bactericidity vs E. coli, } \\
10^{9} \text { Bacteria/L }\end{array}$ & 94 & 80 & 100 & 97 & 0,0048 & 0,997 & 0,06 & 0,98 & 0,075 & $\begin{array}{c}99 \\
0,100\end{array}$ \\
\hline
\end{tabular}

similar level of uricosuria is combined with marked hypouricemia (S2-E+ cluster).

Discriminant analysis (forward stepwise [12]) was conducted to identify exactly the parameters of immunity and microbiota, which together described four clusters differ from each other. The program included in the discriminant model, in addition, by definition, uricemia and uricosuria 8 immune parameters of blood, 2 of saliva, 2 so-called informative parameters, 2 parameters of feces microbiota and 3 parameters of urine that characterize chronic pyelonephritis (Table 3).

Outside the model appeared 8 variables of Leukocytogram and Phagocytosis (Table 4), 6 of Humoral Immunity (Table 5), 5 of Cellular Immunity (Table 6), 3 Proinflammatory factors (Table 7), 4 Informative variables (Table 8), as well as 6 variables of feces and urine Microbiota (Table 9).

The discriminant variables are ranked by criterion Lambda (Table 10). 
Variables of Humoral Immunity, currently not in the mode

\begin{tabular}{|c|c|c|c|c|c|c|c|c|c|c|}
\hline \multirow[t]{2}{*}{ Variables } & \multicolumn{4}{|c|}{$\begin{array}{l}\text { Clusters of Uric Acid } \\
\text { Exchange (n) }\end{array}$} & \multicolumn{5}{|c|}{ Parameters of Wilks' Statistics } & \multirow{2}{*}{ 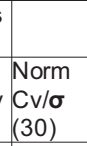 } \\
\hline & $\begin{array}{l}\text { S } \pm E-I I I \\
(30)\end{array}$ & \begin{tabular}{|l}
$\mid$ S2-E+ \\
II \\
$(15)$
\end{tabular} & $\begin{array}{l}S \pm E+ \\
I \\
(21)\end{array}$ & $\begin{array}{l}\text { S-E2+ } \\
\text { IV } \\
(22)\end{array}$ & Wilks & $\begin{array}{l}\text { Par- } \\
\text { tial } \\
\Lambda \\
\end{array}$ & $\begin{array}{l}\text { F-re- } \\
\text { move } \\
(3,7)\end{array}$ & $\begin{array}{l}\text { p- } \\
\text { le-vel }\end{array}$ & $\begin{array}{l}\text { Toler } \\
\text { an-cy }\end{array}$ & \\
\hline $\begin{array}{l}\text { CD22 }{ }^{+} \text {B-Lymphocytes, } \\
\%\end{array}$ & 22,7 & 23,9 & 23,8 & 24,5 & 0,0047 & 0,991 & 0,2 & 0,9 & 0,363 & $\begin{array}{l}20,0 \\
0,175\end{array}$ \\
\hline $\begin{array}{l}\text { Circulating Immune } \\
\text { Complexes, units }\end{array}$ & 35 & 33 & 40 & 35 & 0,0047 & 0,986 & 0,32 & 0,81 & 0,729 & $\begin{array}{c}45 \\
0,389\end{array}$ \\
\hline $\begin{array}{l}\text { gaA Serum, } \\
\mathrm{g} / \mathrm{L}\end{array}$ & 1,85 & 1,64 & 1,85 & 1,67 & 0,0047 & 0,977 & 0,51 & 0,67 & 0,485 & $\begin{array}{l}1,875 \\
0,167\end{array}$ \\
\hline $\begin{array}{l}\mathrm{lg} M \mathrm{M} \text { Serum, } \\
\mathrm{g} / \mathrm{L}\end{array}$ & 1,50 & 1,40 & 1,47 & 1,40 & 0,0047 & 0,976 & 0,52 & 0,67 & 0,718 & $\begin{array}{l}1,15 \\
0,239\end{array}$ \\
\hline $\begin{array}{l}\text { Secretory } \lg \mathrm{A} \\
\text { Saliva, } \mathrm{mg} / \mathrm{L}\end{array}$ & 496 & 496 & 503 & 472 & 0,0047 & 0,978 & 0,49 & 0,69 & 0,189 & $\begin{array}{c}622 \\
0,153\end{array}$ \\
\hline $\begin{array}{l}\mathrm{gG} \text { Saliva, } \\
\mathrm{mg} / \mathrm{L}\end{array}$ & 42,2 & 42,8 & 41,6 & 41,3 & 0,0046 & 0,967 & 0,73 & 0,54 & 0,227 & $\begin{array}{c}36 \\
0,222\end{array}$ \\
\hline
\end{tabular}

Variables of Cellular Immunity, currently not in the mode

\begin{tabular}{|c|c|c|c|c|c|c|c|c|c|c|}
\hline \multirow[b]{2}{*}{ Variables } & \multicolumn{4}{|c|}{$\begin{array}{l}\text { Clusters of Uric Acid } \\
\text { Exchange (n) }\end{array}$} & \multicolumn{5}{|c|}{ Parameters of Wilks' Statistics } & \multirow[b]{2}{*}{$\begin{array}{l}\text { Norm } \\
\text { Cv/ } / \sigma \\
(30)\end{array}$} \\
\hline & \begin{tabular}{|l|} 
S $\pm E-I I I$ \\
$(30)$
\end{tabular} & $\begin{array}{l}\text { S2-E+ } \\
\text { II } \\
(15)\end{array}$ & $\begin{array}{l}\mathrm{S} \pm \mathrm{E}+ \\
\mathrm{I} \\
(21)\end{array}$ & \begin{tabular}{|l} 
S-E2+ \\
IV \\
$(22)$ \\
\end{tabular} & $\begin{array}{l}\text { Wilks } \\
\Lambda\end{array}$ & $\begin{array}{l}\text { Par- } \\
\text { tial } \\
\Lambda \\
\end{array}$ & $\begin{array}{l}\text { F-re- } \\
\text { move } \\
(3,7)\end{array}$ & $\begin{array}{l}\mathrm{p}- \\
\text { level }\end{array}$ & $\begin{array}{l}\text { Toler } \\
\text { ancy }\end{array}$ & \\
\hline $\begin{array}{l}\mathrm{CD}^{+}{ }^{+} \mathrm{CD}^{+}{ }^{+} \mathrm{T}-\mathrm{hel} \text { per } \\
\text { Lymphocytes, } \%\end{array}$ & 32,6 & 32,3 & 30,0 & 28,3 & 0,0046 & 0,967 & 0,73 &, 54 & 0,001 & $\begin{array}{l}39,5 \\
0,082 \\
\end{array}$ \\
\hline $\begin{array}{l}\mathrm{CD}^{+}{ }^{+} \mathrm{CD} 3^{+} \mathrm{T} \text {-cytolytic } \\
\text { Lymphocytes, } \%\end{array}$ & 23,3 & 21,2 & 23,4 & 23,7 & 0,0047 & 0,983 & 0,37 & 0,78 & 0,613 & $\begin{array}{l}23,5 \\
0,138 \\
\end{array}$ \\
\hline $\begin{array}{l}\text { CD3 }{ }^{+} \text {T-active } \\
\text { Lymphocytes, } \%\end{array}$ & 29,0 & 297 & 28,4 & 28,6 & 0,0047 & 0,978 & 0,5 & 0,69 & 0,648 & $\begin{array}{l}30,0 \\
0,167\end{array}$ \\
\hline $\begin{array}{l}\text { CD56 }{ }^{+} \text {Natural Killer } \\
\text { Lymphocytes, \% }\end{array}$ & 18,9 & 20,7 & 20,4 & 21,2 & 47 & 82 & 0,4 & ,76 & 0,24 & $\begin{array}{r}17,0 \\
0,172\end{array}$ \\
\hline $\begin{array}{l}\text { 0-Lymphocytes } \\
\text { of Blood, \% }\end{array}$ & 2,5 & 1,8 & 2,4 & 2,3 & 0,0048 & 0,996 & 0,09 & 0,97 & 0,295 & $\begin{array}{c}0 \\
5,56\end{array}$ \\
\hline
\end{tabular}

Table 7 t

\begin{tabular}{|c|c|c|c|c|c|c|c|c|c|c|}
\hline \multirow[b]{2}{*}{ Variables } & \multicolumn{4}{|c|}{$\begin{array}{l}\text { Clusters of Uric Acid } \\
\text { Exchange (n) }\end{array}$} & \multicolumn{5}{|c|}{ Parameters of Wilks' Statistics } & \multirow[b]{2}{*}{$\begin{array}{l}\text { Norm } \\
\text { Cv/ } / \\
(30)\end{array}$} \\
\hline & $\begin{array}{l}\text { S } \pm E-\text { IIII } \\
(30)\end{array}$ & \begin{tabular}{|l} 
S2-E+ \\
II \\
$(15)$
\end{tabular} & $\begin{array}{l}\mathrm{S} \pm \mathrm{E}+ \\
\mathrm{l} \\
(21)\end{array}$ & $\begin{array}{l}\text { S-E2+ } \\
\text { IV } \\
(22)\end{array}$ & $\begin{array}{l}\text { Wilks } \\
\Lambda\end{array}$ & $\begin{array}{l}\text { Par- } \\
\text { tial } \\
\Lambda \\
\end{array}$ & $\begin{array}{l}\text { F-re- } \\
\text { move } \\
(3,7)\end{array}$ & $\begin{array}{l}\text { p- } \\
\text { level }\end{array}$ & $\begin{array}{l}\text { Toler } \\
\text { ancy }\end{array}$ & \\
\hline $\begin{array}{l}\text { Interleukin-1, } \\
\text { ng/L }\end{array}$ & 4,58 & 5,34 & 4,74 & 4,81 & 0,005 & 0,975 & 50,560 & 0,650 & 0,522 & $2 \begin{array}{l}4,51 \\
0,173 \\
\end{array}$ \\
\hline $\begin{array}{l}\text { Tumor Necrosis } \\
\text { Factor- } \alpha, \text { ng/L }\end{array}$ & 6,21 & 5,87 & 5,76 & 6,13 & 0,005 & 1,000 & 0,000 & 1,000 & 0,648 & $\begin{array}{l}4,90 \\
0,326 \\
\end{array}$ \\
\hline $\begin{array}{l}\text { C-Reactive Protein, } \\
\text { ng/L }\end{array}$ & 2,60 & 2,46 & 2,41 & 2,57 & 0,005 & 51,000 & 0,000 & 1,000 & 0,485 & \begin{tabular}{|l|l|}
2,18 \\
0,324 \\
\end{tabular} \\
\hline
\end{tabular}

\begin{tabular}{|c|c|c|c|c|c|c|c|c|c|c|}
\hline \multirow[b]{3}{*}{ Variables } & & & & & & & & & & \\
\hline & \multicolumn{4}{|c|}{$\begin{array}{l}\text { Clusters of Uric Acid } \\
\text { Exchange (n) }\end{array}$} & \multicolumn{5}{|c|}{ Parameters of Wilks' Statistics } & \multirow[b]{2}{*}{$\begin{array}{l}\text { Norm } \\
\mathrm{Cv} / \boldsymbol{\sigma} \\
(30)\end{array}$} \\
\hline & $\begin{array}{l}S \pm E-I I I \\
(30)\end{array}$ & \begin{tabular}{|l} 
S2-E+ \\
II \\
(15)
\end{tabular} & $\begin{array}{l}S \pm E+ \\
1 \\
(21)\end{array}$ & $\begin{array}{l}\text { S-E2+ } \\
\text { IV } \\
(22)\end{array}$ & $\begin{array}{l}\text { Wilks } \\
\Lambda\end{array}$ & $\begin{array}{l}\text { Par- } \\
\text { tial } \\
\Lambda \\
\end{array}$ & \begin{tabular}{|l} 
F-re- \\
move \\
$(3,7)$ \\
\end{tabular} & $\begin{array}{l}\text { p- } \\
\text { level }\end{array}$ & $\begin{array}{l}\text { Toler } \\
\text { ancy }\end{array}$ & \\
\hline $\begin{array}{l}\text { Entropy of } \\
\text { Leukocytogram }\end{array}$ & 0,647 & 0,653 & 0,651 & 0,660 & 0,0048 & 80,997 & 0,07 & 0,98 & 0,659 & $\begin{array}{l}0,681 \\
0,070 \\
\end{array}$ \\
\hline $\begin{array}{l}\text { Popovych's Strain } \\
\text { Index-2, points }\end{array}$ & 0,18 & 0,21 & 0,39 & 0,18 & 0047 & 70,978 & 0,5 & 0,69 & 0,088 & $\begin{array}{l}0,065 \\
0,618\end{array}$ \\
\hline $\begin{array}{l}\text { Popovych's Adaptation } \\
\text { Index-1, points }\end{array}$ & 1,17 & 1,16 & 1,07 & 1,06 & 0,0047 & $\begin{array}{ll}7 & 0,98\end{array}$ & 0,45 & 0,72 & 0,469 & \begin{tabular}{|l}
1,70 \\
0,147
\end{tabular} \\
\hline $\begin{array}{l}\text { Popovych's Adaptation } \\
\text { Index-2, points }\end{array}$ & 0,84 & 0,82 & 0,81 & 0,77 & 0,0046 & 60,971 & 0,64 & 0,59 & 0,524 & $\begin{array}{l}1,70 \\
0,147\end{array}$ \\
\hline
\end{tabular}

Table 8

$$
8
$$
variables with canonical discriminant Roots, the cluster centroids of Roots, and the normalized values of the discriminant variables as well as variables currently not in the model but worth the attention.
Next, the 19-dimensional space of discriminant variables transforms into 3-dimensional space of canonical roots. The canonical correlation coefficient is for Root 10,950 (Wilks' $\Lambda=0,030 ; \chi_{(57)}^{2}=264 ; p<10^{-6}$ ), for Root
As we can see, the major root is uniquely interpreted as uricosuria Together with it, the root condenses information on the entropy of the immunocytogram (ICG) and, in the reverse way, the intensity of ph- 
Variables of Microbiota, currently not in the model

\begin{tabular}{|c|c|c|c|c|c|c|c|c|c|c|}
\hline \multirow[b]{2}{*}{ Variables } & \multicolumn{4}{|c|}{$\begin{array}{l}\text { Clusters of Uric Acid } \\
\text { Exchange (n) }\end{array}$} & \multicolumn{5}{|c|}{ Parameters of Wilks' Statistics } & \multirow[b]{2}{*}{$\begin{array}{l}\text { Norm } \\
\text { Cv/ } \boldsymbol{\sigma} \\
(30)\end{array}$} \\
\hline & $\begin{array}{l}\mathrm{S} \pm \mathrm{E}-\mathrm{III} \\
(30)\end{array}$ & \begin{tabular}{|l} 
S2-E+ \\
II \\
$(15)$ \\
\end{tabular} & $\begin{array}{l}\mathrm{S} \pm \mathrm{E}+ \\
(21) \\
(21)\end{array}$ & $\begin{array}{l}\text { S-E2+ } \\
\text { IV } \\
(22) \\
\end{array}$ & $\begin{array}{l}\text { Wilks } \\
\Lambda\end{array}$ & $\begin{array}{l}\text { Par- } \\
\text { tial } \\
\Lambda\end{array}$ & $\begin{array}{l}\text { F-re- } \\
\text { move } \\
(3,7)\end{array}$ & $\begin{array}{l}\text { p- } \\
\text { le-vel }\end{array}$ & $\begin{array}{l}\text { Toler } \\
\text { an-cy }\end{array}$ & \\
\hline $\begin{array}{l}\text { E. coli faeces, } \\
\text { Ig CFU/g }\end{array}$ & 8,28 & 8,28 & 8,23 & 8,28 & 0,005 & 1,000 & 0,000 & 1,000 & 0,613 & $\begin{array}{l}8,66 \\
0,030\end{array}$ \\
\hline $\begin{array}{l}\text { Atten uated E. coli } \\
\text { faeces, } \%\end{array}$ & 60 & 66 & 53 & 56 & 0,005 & 0,997 & 0,080 & 0,970 & 0,110 & $\begin{array}{c}17,4 \\
1,0\end{array}$ \\
\hline $\begin{array}{l}\text { Hemolytic E. coli } \\
\text { faeces, } \%\end{array}$ & 13 & 26 & 20 & 10 & 0,005 & 0,976 & 0,520 & 0,670 & 0,432 & $\begin{array}{c}0 \\
25\end{array}$ \\
\hline $\begin{array}{l}\text { Klebsiela\&Proteus } \\
\text { faeces, } \%\end{array}$ & 11,2 & 8,8 & 18,2 & 13,1 & 0,005 & 0,982 & 0,400 & 0,750 & 0,146 & $\begin{array}{c}10 \\
0,500\end{array}$ \\
\hline $\begin{array}{l}\text { Bacteriuria, } \\
\text { Ig CFU } / \mathrm{mL}\end{array}$ & 1,19 & 1,79 & 1,05 & 1,21 & 0,005 & 0,976 & 0,530 & 0,670 & 0,077 & $\begin{array}{c}0 \\
0,98\end{array}$ \\
\hline $\begin{array}{l}\text { Leukocyturia, } \\
\text { points }\end{array}$ & 0,15 & 0,10 & 0,15 & 0,19 & 0,005 & 0,977 & 0,500 & 0,680 & 0,162 & $\begin{array}{c}0 \\
0,15\end{array}$ \\
\hline $\begin{array}{l}\text { Erhytrocyturia, } \\
\mathrm{lg} / \mathrm{mL}\end{array}$ & 3,09 & 3,01 & 2,94 & 3,13 & 0,005 & 0,982 & 0,400 & 0,750 & 0,172 & $\begin{array}{l}2,70 \\
0,095\end{array}$ \\
\hline
\end{tabular}

Summary of Stepwise Analysis for Variables of Uric Acid Exchange, Immunity and Microbiota

\begin{tabular}{|c|c|c|c|c|c|}
\hline $\begin{array}{c}\text { Variables } \\
\text { currently in the model }\end{array}$ & $\begin{array}{l}\mathrm{F} \text { to } \\
\text { enter }\end{array}$ & p-level & $\Lambda$ & $\begin{array}{l}\text { F-va- } \\
\text { lue }\end{array}$ & $\begin{array}{c}\mathrm{p}- \\
\text { level }\end{array}$ \\
\hline Uric Acid excretion, Z-score & 154 & $10^{-6}$ & 0,154 & 154 & $10^{-6}$ \\
\hline Serum Uric Acid level, Z-score & 13,5 & $10^{-6}$ & 0,104 & 58,3 & $10^{-6}$ \\
\hline Popovych's Strain Index-1, points & 2,3 & 0,079 & 0,095 & 36,1 & $10^{-6}$ \\
\hline Killing Index vs Staphylococcus aureus, $\%$ & 2,1 & 0,108 & 0,089 & 26,8 & $10^{-6}$ \\
\hline Lysozime Saliva, mg/L & 2,2 & 0,096 & 0,082 & 21,8 & $10^{-6}$ \\
\hline Phagocytose Index vs Staphylococcus aureus, $\%$ & 2,3 & 0,084 & 0,075 & 18,6 & $10^{-6}$ \\
\hline Pan-Lymphocytes of Blood, \% & 2,2 & 0,09 & 0,069 & 16,4 & $10^{-6}$ \\
\hline Phagocytose Index vs Escherichia coli, \% & 2,0 & 0,119 & 0,064 & 14,7 & $10^{-6}$ \\
\hline Eryth rocyturia, points & 2,2 & 0,096 & 0,059 & 13,5 & $10^{-6}$ \\
\hline IgA Saliva, mg/L & 1,6 & 0,208 & 0,056 & 12,3 & $10^{-6}$ \\
\hline Bifidobacterium faeces, Ig CFU/g & 1,7 & 0,167 & 0,052 & 11,5 & $10^{-6}$ \\
\hline Lactobacillus faeces, lg CFU/g & 1,6 & 0,194 & 0,049 & 10,7 & $10^{-6}$ \\
\hline Leukocyturia, Ig/L & 1,4 & 0,254 & 0,046 & 10,0 & $10^{-6}$ \\
\hline IgG Serum, g/L & 1,3 & 0,29 & 0,044 & 9,4 & $10^{-6}$ \\
\hline Bacteriuria, points & 1,8 & 0,161 & 0,041 & 9,0 & $10^{-6}$ \\
\hline Bactericidity vs Staphyl. aureus, $10^{9}$ Bacteria/L & 2,8 & 0,046 & 0,036 & 8,8 & $10^{-6}$ \\
\hline Entropy of Immunocytogram & 1,1 & 0,338 & 0,005 & 19,0 & $10^{-6}$ \\
\hline Interleukin-6, ng/L & 1,5 & 0,21 & 0,005 & 18,1 & $10^{-6}$ \\
\hline Microbial Count vs E. coli, Bacteria/Phagocyte & 1,5 & 0,233 & 0,005 & 17,3 & $10^{-6}$ \\
\hline
\end{tabular}

Standardized and Raw Coefficients and Constants for Variables of Uric Acid exchange, Immunity and Microbiota

\begin{tabular}{|c|c|c|c|c|c|c|}
\hline \multirow[t]{2}{*}{ Coefficients } & \multicolumn{3}{|c|}{ Standardized } & \multicolumn{3}{|c|}{ Raw } \\
\hline & Root 1 & Root 2 & Root 3 & Root 1 & Root 2 & Root 3 \\
\hline Uric Acid excretion, Z-score & 1,223 & 0,017 & 0,043 & 1,523 & 0,021 & 0,054 \\
\hline Serum Uric Acid level, Z-score & 0,083 & $-0,832$ & $-0,123$ & 0,088 & $-0,889$ & $-0,131$ \\
\hline Popovych's Strain Index-1, points & 0,002 & $-0,242$ & $-0,28$ & 0,012 & $-1,292$ & $-1,493$ \\
\hline Killing Index vs Staph. au reus, $\%$ & 0,062 & $-0,356$ & $-0,074$ & 0,007 & $-0,042$ & $-0,009$ \\
\hline Lysozime Saliva, mg/L & 0,204 & $-0,14$ & $-1,296$ & 0,03 & $-0,021$ & $-0,193$ \\
\hline Phag ocytose Index vs Staph. aur,, $\%$ & 0,563 & 0,247 & $-0,683$ & 0,478 & 0,21 & $-0,58$ \\
\hline Pan-Lymphocytes of Blood, \% & $-0,661$ & 0,239 & 0,188 & $-0,086$ & 0,031 & 0,025 \\
\hline Phagocytose Index vs E. coli, $\%$ & $-0,327$ & $-0,061$ & 0,931 & $-0,247$ & $-0,046$ & 0,703 \\
\hline Erythro cyturia, points & $-0,049$ & $-0,148$ & 0,455 & $-0,493$ & $-1,506$ & 4,621 \\
\hline IgA Saliva, mg/L & $-0,704$ & 0,399 & 0,06 & $-0,02$ & 0,012 & 0,002 \\
\hline Bifido bacterium faeces, Ig CFU/g & $-1,357$ & 0,214 & 4,01 & $-1,165$ & 0,184 & 3,443 \\
\hline Lactobacillus faeces, $\lg$ CFU/g & 1,355 & $-0,15$ & $-3,68$ & 0,949 & $-0,105$ & $-2,577$ \\
\hline Leuko cyturia, Ig/L & $-0,381$ & $-0,056$ & 0,987 & $-0,571$ & $-0,084$ & 1,479 \\
\hline IgG Serum, g/L & $-0,301$ & $-0,203$ & 0,238 & $-0,081$ & $-0,055$ & 0,064 \\
\hline Bacteriuria, points & $-0,051$ & 0,937 & $-0,463$ & $-0,21$ & 3,855 & $-1,903$ \\
\hline Bactericidity vs Staph. aur, $10^{\circ} \mathrm{Bac} / \mathrm{L}$ & $-0,279$ & 0,689 & $-0,766$ & $-0,011$ & 0,028 & $-0,031$ \\
\hline Entropy of Immu nocytogram & $-0,344$ & 0,274 & $-0,095$ & $-12,89$ & 10,26 & $-3,568$ \\
\hline Interleukin-6, ng/L & $-0,475$ & 0,365 & 0,522 & $-1,808$ & 1,389 & 1,98 \\
\hline Microbial Count vs E. coli, Bact/Phag & 0,072 & 0,091 & 0,654 & 0,008 & 0,011 & 0,077 \\
\hline & & & Constants & 7,317 & $-38,510$ & $-3,494$ \\
\hline & & & Eigenvalues & 9,266 & 0,850 & 0,732 \\
\hline & & Cum & ulative Prop. & 0,854 & 0,933 & 1,000 \\
\hline
\end{tabular}

agocytosis by neutrophils of both bacteria, the content of IgA and lysozyme in saliva and $\lg \mathrm{G}$ in serum. Such uricous-immune relation-
Table 10

Table 9 ships are visualized (Fig. 2) by the localization of members of the $\mathrm{S} \pm \mathrm{E}$ - cluster in the negative zone of the root axis, reflecting the combination of hypouricosuria with a slight neg-entropy of ICG, on the one hand, and maximally for sampling increased phagocytosis activity against $\mathrm{E}$. coli and IgG content in serum while minimally for sampling reduced IgA content in saliva, on the other hand.

Instead, in the positive zone of the axis localized members of the cluster S-E2+, in which hyperuricosuria is accompanied by a slightly increased ICG entropy, minimal for the sample increase in serum IgG, lack of activation of phagocytosis and maximum for the sample decrease in IgA and lysozyme saliva content.

The members of the other two clusters with equally moderate hyperuricosuria occupy an intermediate quasi-zero zone of the axis, reflecting the intermediate state of these immune parameters.

By adding monocytes and T-helper cells not included in the model, we obtain immuno-enhancing and immuno-suppressive patterns for uricosuria (Fig. 3). 
Correlations Variables-Canonical Roots, Means of Roots and Z-scores of Variables of Uric Acid exchange, Immunity and Microbiota

\begin{tabular}{|c|c|c|c|c|c|c|c|}
\hline Variables & \multicolumn{3}{|c|}{$\begin{array}{c}\text { Correlations } \\
\text { Variables-Roots }\end{array}$} & $\begin{array}{l}\mathrm{S} \pm \mathrm{E}-\mathrm{III} \\
(30)\end{array}$ & \begin{tabular}{|l} 
S2-E+ \\
II (15)
\end{tabular} & $\begin{array}{l}\mathrm{S} \pm \mathrm{E}+ \\
\mathrm{I}(21)\end{array}$ & \begin{tabular}{|l|} 
S-E2+ \\
IV $(22)$
\end{tabular} \\
\hline Root $1(85,4 \%)$ & R 1 & R 2 & R 3 & $-3,51$ & $-0,09$ & $+0,61$ & 4,27 \\
\hline Uric Acid excretion & 0,768 & 0,13 & 0,161 & $-0,97$ & $+1,17$ & $+1,26$ & $+3,87$ \\
\hline Entropy of Immunocytogram & 0,057 & $-0,013$ & $-0,099$ & $-0,07$ & $+0,07$ & $+0,13$ & $+0,13$ \\
\hline Monocytes & \multicolumn{3}{|c|}{ currently not in model } & $-1,22$ & 0,00 & $+0,36$ & $+0,65$ \\
\hline Phagocytose Index vs E. coli & $-0,097$ & $-0,106$ & $-0,048$ & $+0,96$ & $+0,42$ & $+0,70$ & $+0,09$ \\
\hline IgA Saliva & $-0,095$ & 0,061 & $-0,108$ & $-2,71$ & $-2,73$ & $-2,80$ & $-2,97$ \\
\hline Lysozime Saliva & $-0,073$ & $-0,042$ & $-0,18$ & $-0,28$ & $-0,31$ & $-0,27$ & $-0,42$ \\
\hline $\begin{array}{l}\text { Phagocytose Index vs Staph. } \\
\text { aureus }\end{array}$ & $-0,043$ & 0,009 & $-0,121$ & $+0,37$ & $+0,40$ & $+0,39$ & $+0,14$ \\
\hline IgG Serum & $-0,041$ & $-0,075$ & 0,023 & $+1,10$ & $+0,65$ & $+0,89$ & $+0,64$ \\
\hline $\mathrm{CD4}^{+} \mathrm{CD}^{+}{ }^{+}$T-helper Lymphocytes & \multicolumn{3}{|c|}{ currently not in model } & $-2,12$ & $-2,21$ & $-2,93$ & $-3,47$ \\
\hline Root $2(8,0 \%)$ & R 1 & R 2 & R 3 & $-0,18$ & $+1,82$ & $-0,99$ & $-0,04$ \\
\hline Uric Acid Serum & $-0,008$ & $-0,743$ & $-0,05$ & $-0,53$ & $-1,89$ & $+0,09$ & $-0,70$ \\
\hline Killing Index vs Staph. aureus & 0,033 & $-0,181$ & $-0,186$ & $-1,25$ & $-1,32$ & $-0,70$ & $-1,12$ \\
\hline Bactericidity vs Staph. aureus & 0,003 & $-0,163$ & $-0,118$ & $-1,06$ & $-1,43$ & $-0,25$ & $-1,12$ \\
\hline Bactericidity vs E. coli & \multicolumn{3}{|c|}{ currently not in model } & $-0,50$ & $-1,92$ & $+0,14$ & $-0,20$ \\
\hline $\begin{array}{l}\text { CD8 }^{+}{ }^{C D} 3^{+} \text {T-cytolytic } \\
\text { Lymphocytes }\end{array}$ & \multicolumn{3}{|c|}{ currently not in model } & 6 & 1 & 4 & 66 \\
\hline Microbial Count vs E. coli & $-0,014$ & $-0,103$ & $-0,026$ & $+0,94$ & $+0,76$ & $+0,99$ & $+0,83$ \\
\hline Leukocyturia, Ig & $-0,004$ & $-0,061$ & 0,177 & $+0,89$ & $+0,39$ & $+0,51$ & $+0,88$ \\
\hline Lactobacillus faeces & 0,008 & $-0,05$ & 0,069 & $-1,19$ & $-1,35$ & $-1,24$ & $-1,12$ \\
\hline Bifidobacterium faeces & 0,002 & $-0,043$ & 0,106 & $-1,13$ & $-1,35$ & $-1,27$ & $-1,09$ \\
\hline Bacteriuria, points & 0,003 & 0,308 & $-0,033$ & $+1,11$ & $+1,75$ & $+0,93$ & $+1,17$ \\
\hline Bacteriuria, Ig & \multicolumn{3}{|c|}{ currently not in model } & $+1,21$ & $+1,82$ & $+1,07$ & $+1,23$ \\
\hline Attenuated E. coli faeces & \multirow{2}{*}{\multicolumn{3}{|c|}{$\begin{array}{l}\text { currently not in model } \\
\text { currently not in model }\end{array}$}} & $+2,47$ & $+2,79$ & $+2,07$ & $+2,21$ \\
\hline Interleukin-1 & & & & $+0,09$ & $+1,06$ & $+0,29$ & $+0,38$ \\
\hline Pan-Lymphocytes & 0,005 & 0,175 & 0,095 & $+0,34$ & $+0,68$ & $-0,05$ & $+0,40$ \\
\hline Root $3(6,6 \%)$ & R 1 & R 2 & R 3 & $+0,59$ & $-0,74$ & $-1,16$ & $+0,81$ \\
\hline Popovych's Strain Index-1 & 0,01 & $-0,135$ & $-0,287$ & $+1,29$ & $+1,87$ & $+3,83$ & $+1,28$ \\
\hline Klebsiela\&Proteus faeces & \multicolumn{3}{|c|}{ currently not in model } & $+0,23$ & $-0,24$ & $+1,64$ & $+0,62$ \\
\hline Eryth rocyturia, points & $-0,006$ & $-0,023$ & 0,271 & $+1,22$ & $+0,80$ & $+0,75$ & $+1,23$ \\
\hline Interleukin-6 & 0,014 & $-0,061$ & 0,112 & $+0,90$ & $+0,74$ & $+0,69$ & $+0,86$ \\
\hline Tumor Necros is Factor- $\alpha$ & \multicolumn{3}{|c|}{ currently not in model } & $+0,82$ & $+0,62$ & $+0,54$ & $+0,77$ \\
\hline C-Reactive Protein & \multicolumn{3}{|c|}{ currently not in model } & $+0,60$ & $+0,39$ & $+0,32$ & $+0,55$ \\
\hline
\end{tabular}

Squared Mahalanobis Distances between Clusters, F-values $(d f=19,7)$ and p-levels

\begin{tabular}{|c|c|c|c|c|}
\hline Clusters & $\begin{array}{c}\mathrm{S} \pm \mathrm{E}+ \\
\mathrm{I}\end{array}$ & $\begin{array}{c}\text { S2-E+ } \\
\text { II }\end{array}$ & $\begin{array}{c}\text { S-E2+ } \\
\text { IV }\end{array}$ & SEE-III \\
\hline $\begin{array}{l}\text { S } \pm E+ \\
\text { I (21) }\end{array}$ & 0 & 9,1 & 19,5 & 21,7 \\
\hline $\begin{array}{l}\text { S2-E+ } \\
\text { II (15) }\end{array}$ & $\begin{array}{c}3,1 \\
10^{-3}\end{array}$ & 0 & 26,2 & 18,3 \\
\hline $\begin{array}{l}\text { S-E2+ } \\
\text { IV (22) }\end{array}$ & $\begin{array}{l}8,3 \\
10^{-6}\end{array}$ & $\begin{array}{c}9,1 \\
10^{-6}\end{array}$ & 0 & 63,7 \\
\hline $\begin{array}{l}\text { S } \pm \text { E- } \\
\text { III (30) }\end{array}$ & $\begin{array}{l}10,6 \\
10^{-6}\end{array}$ & $\begin{array}{l}7,1 \\
10^{-6} \\
\end{array}$ & $\begin{array}{c}32,1 \\
10^{-6} \\
\end{array}$ & 0 \\
\hline
\end{tabular}

Coefficients and Constants for Classification Functions of Clusters

Table 14

\begin{tabular}{|c|c|c|c|c|}
\hline Clusters & $\begin{array}{c}\mathrm{S} \pm \mathrm{E}+ \\
\mathrm{I}\end{array}$ & $\begin{array}{c}\text { S2-E+ } \\
\text { II }\end{array}$ & $\begin{array}{c}\text { S-E2+ } \\
\text { IV }\end{array}$ & $\begin{array}{c}\text { SEE- } \\
\text { III }\end{array}$ \\
\hline Variables & $p=0,239$ & $p=0,170$ & $p=0,250$ & $p=0,341$ \\
\hline Uric Acid excretion, Z-score & $-5,524$ & $-6,483$ & 0,233 & $-11,67$ \\
\hline Serum Uric Acid level, Z-score & $-66,14$ & $-68,88$ & $-67,14$ & $-67,53$ \\
\hline Popovych's Strain Index-1, points & $-67,95$ & $-72,32$ & $-72,26$ & $-71,73$ \\
\hline Killing Index vs Staph. aureus, $\%$ & 6,538 & 6,41 & 6,506 & 6,458 \\
\hline Lysozime Saliva, mg/L & $-0,192$ & $-0,363$ & $-0,499$ & $-0,678$ \\
\hline Phagocytose Index vs Staph. aureus, \% & 118,4 & 118,5 & 119,3 & 115,7 \\
\hline Pan-Lymphocytes of Blood, \% & $-5,873$ & $-5,732$ & $-6,143$ & $-5,459$ \\
\hline Phagocytose Index vs E. coli, \% & 69,08 & 69,51 & 69,67 & 71,34 \\
\hline Erythrocyturia, points & $-150,3$ & $-152,2$ & $-144,3$ & $-141,3$ \\
\hline IgA Saliva, mg/L & $-1,631$ & $-1,588$ & $-1,699$ & $-1,537$ \\
\hline Bifidobacterium faeces, Ig CFU/g & $-12,09$ & $-9,259$ & $-9,291$ & $-1,077$ \\
\hline Lactobacillus faeces, Ig CFU/g & $-13,36$ & $-15,21$ & $-14,74$ & $-21,76$ \\
\hline Leukocyturia, Ig/L & 238,1 & 239 & 239,1 & 243 \\
\hline IgG Serum, g/L & 0,326 & 0,271 & 0,129 & 0,739 \\
\hline Bacteriuria, points & 138,8 & 149,4 & 138,7 & 139,7 \\
\hline Bactericidity vs Staph. aureus, $10^{9}$ Bacteria/L & $-1,871$ & $-1,796$ & $-1,948$ & $-1,856$ \\
\hline Entropy of Immunocytogram & 3605 & 3637 & 3552 & 3658 \\
\hline Interleukin-6, ng/L & 580,9 & 586,6 & 579,1 & 592,8 \\
\hline Microbial Count vs E. coli, Bacter/Phagocyte & $-6,096$ & $-6,036$ & $-5,897$ & $-5,985$ \\
\hline Constants & -13393 & -13514 & -13427 & -13468 \\
\hline
\end{tabular}

The separation of the last two clusters occurs along the axis of the second root, which represents inverted uricemia The upper position of the members of the S2-E+ cluster reflects a combination of hypouricemia in them with a maximum for sampling inhibition of the completion of Staph. aureus phagocytosis, a minimum of Leukocyturia and activation of the intensity of E. coli phagocytosis, as well as maximum reduction in the microbiota of beneficial Lactobacillus and Bifidobacterium, which are inversely related to the root. Instead, panlymphocytes and bacteriuria (estimated on a one-point scale [10]) levels, which are directly related to the root, are maximal for sampling.

The lower position of the $\mathrm{S} \pm \mathrm{E}+$ cluster members reflects a combination of normal uricemia with normal or less reduced/ elevated levels of the listed immunity parameters and microbiota negatively/positively associated with the second root.

Taking into account not included in the model T-cytolytic lymphocytes, bacteri- 


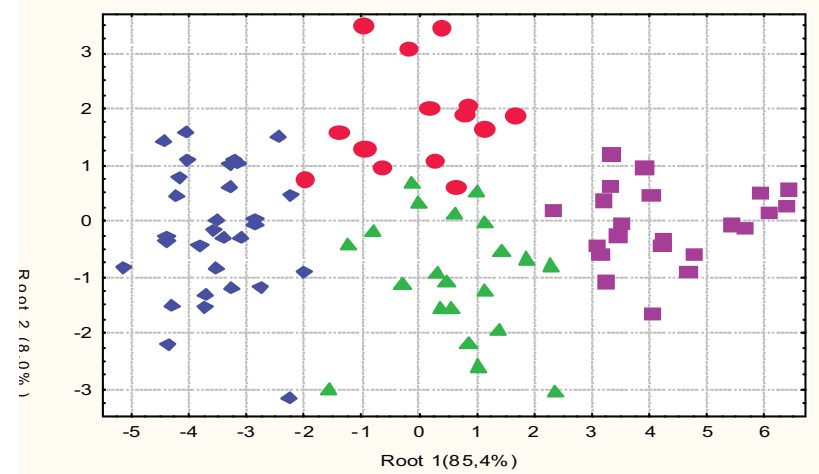

Fig. 2. Scatterplot of patients from differ clusters in space of first and second Roots

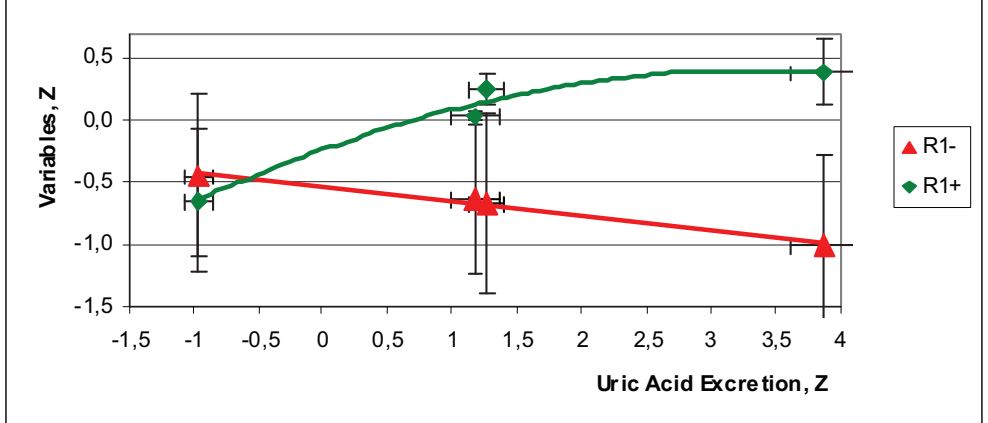

Fig. 3. Patterns of Immunity parameters, the information of which is condensed in the first Root

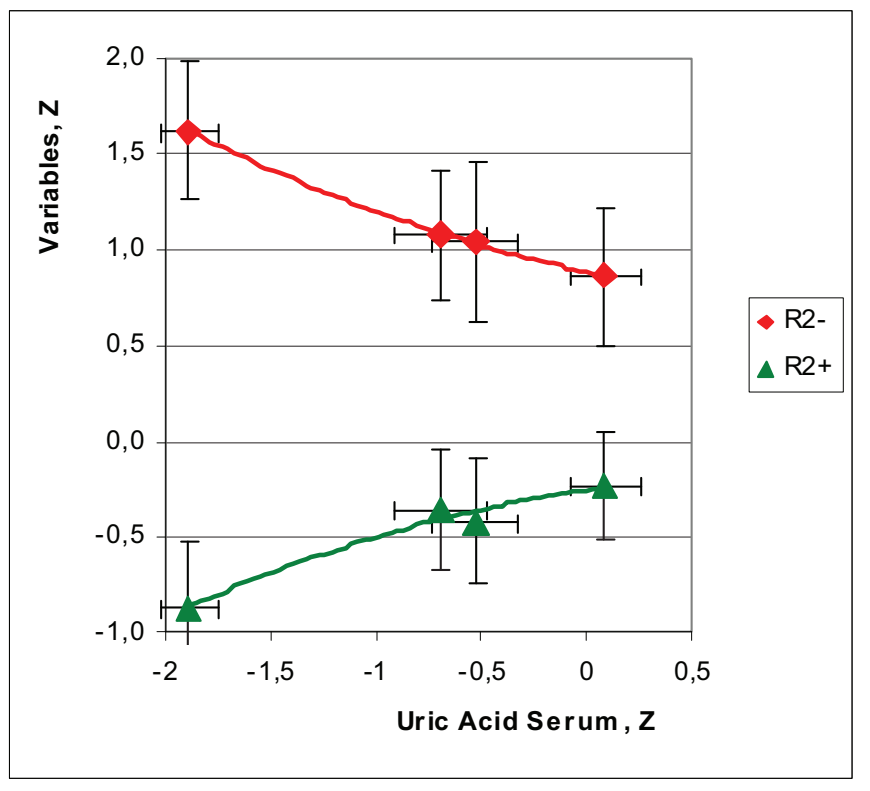

Fig. 4. Patterns of Immunity parameters, the information of which is condensed in the second Root

cidal activity against $\mathrm{E}$. coli, row bacteriuria, relative content of E. coli with impaired enzymatic activity in the microbiota and plasma IL-1 level, we have formed immuno-enhanc-
$S+-E+(I)$ $S--E+($ II) S+-E-(III)

ing and immuno-suppressive patterns of uricemia (Fig. 4).

In the information space of the two roots, which together condense $93,4 \%$ of the discriminatory information, all four clusters are visually clearly separated, with some exceptions (Fig. 2).

Additional delimitation of the members of the $\mathrm{S} \pm \mathrm{E}+$ cluster occurs along the axis of the third root, due to the maximum elevated Popovych's Strain Index1 , the relative content in microbiota of the Klebsiela\&Proteus and Erythrocyturia, instead of the minimally increased levels of proinflammatory factors (Figs. 5 and 6).

In general, cluster delineation is highly reliable (Table 13).

The same discriminant variables can be used to identify the belonging of one or another person to one or another cluster. This purpose of discriminant analysis is realized with the help of classifying functions (Table 14).

We can retrospectively recognize members of III cluster unmistakably, of IV cluster with one error, but of I and II clusters with two errors (Table 15).

\section{Acknowledgment}

We express sincere gratitude to administration JSC "Truskavets'kurort" and "Truskavets' SPA" as well as clinical sanatorium "Moldova" for help in conducting this investigation. 
Classification Matrix for Clusters Rows: Observed classifications; Columns: Predicted classifications

\begin{tabular}{|l|l|l|l|l|l|}
\hline \multirow{2}{*}{ Clusters } & \multirow{2}{*}{$\begin{array}{c}\text { Percent } \\
\text { correct }\end{array}$} & \multicolumn{1}{c|}{$\begin{array}{c}\text { S } \pm \text { IE+ } \\
\text { I }\end{array}$} & \multicolumn{1}{c|}{$\begin{array}{c}\text { S2-E+ } \\
\text { II }\end{array}$} & $\begin{array}{c}\text { S-E2+ } \\
\text { IV }\end{array}$ & $\begin{array}{c}\text { S } \pm \text { E- } \\
\text { III }\end{array}$ \\
\cline { 2 - 6 } & & $\mathrm{p}=0,239$ & $\mathrm{p}=0,170$ & $\mathrm{p}=0,250$ & $\mathrm{p}=0,341$ \\
\hline $\mathrm{I}$ & 90,5 & $\mathbf{1 9}$ & $\mathbf{2}$ & 0 & 0 \\
\hline $\mathrm{II}$ & 86,7 & 1 & 13 & 0 & 1 \\
\hline IV & 95,5 & 1 & 0 & $\mathbf{2 1}$ & 0 \\
\hline III & 100 & 0 & 0 & 0 & 30 \\
\hline Total & 94,3 & 21 & 15 & 21 & 31 \\
\hline
\end{tabular}

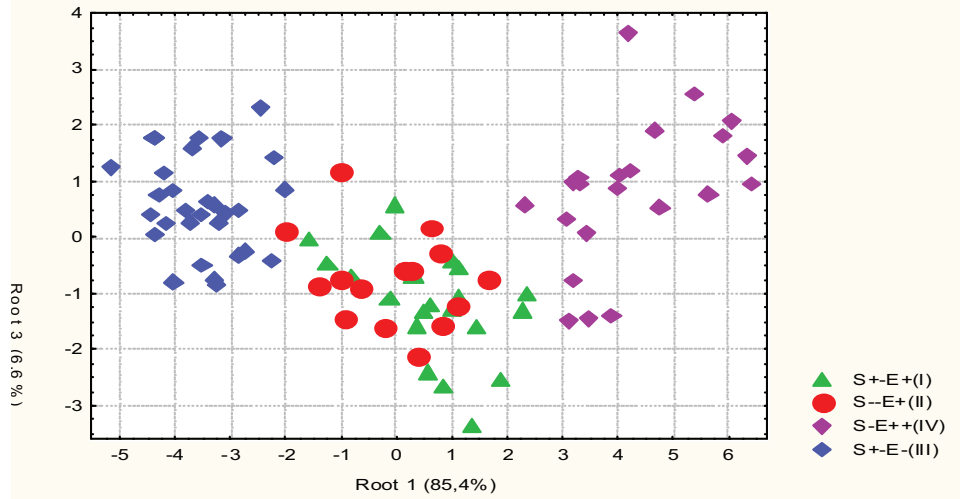

Fig. 5. Scatterplot of patients from differ clusters in space of first and third Roots

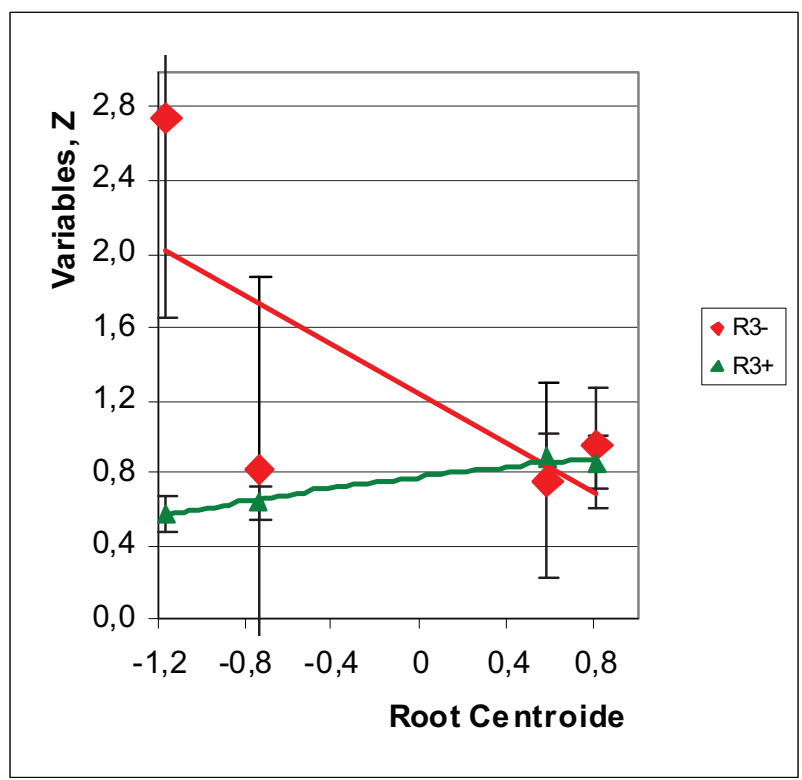

Fig. 6. Patterns of Immunity parameters, the information of which is condensed in the third Root

\section{Accordance to ethics standards}

Tests in patients are conducted in accordance with positions of Helsinki Declaration 1975, revised and complemented in 2002, and directive of National Committee on ethics of scientific researches. During realization of tests from all participants the informed consent is got and used all measures
Table 15 for providing of anonymity of participants.

\section{References}

1. Aldenderfer MS, Blashfield RK. Cluster analysis (Second printing, 1985) [trans. from English in Russian]. In: Factor, Discriminant and Cluster Analysis. Moskva. Finansy i Statistika; 1989: 139-214.

2. Barylyak LG, Malyuchkova RV, Tolstanov OB, Tymochko OB, Hryvnak RF, Uhryn MR. Comparative estimation of informativeness of leucocytary index of adaptation by Garkavi and by Popovych. Medical Hydrology and Rehabilitation. 2013; 11(1): 520.

3. Douglas SD, Quie PG. Investigation of Phagocytes in Disease. Churchil; 1981: 110 p.

4. Goryachkovskiy AM. Clinical Biochemistry [in Russian]. Odesa. Astroprint; 1998: 608 p.

5. Gozhenko Al, Smagliy VS, Korda IV, Zukow W, Popovych IL. Cluster analysis of uric acid exchange parameters in female rats. Journal of Education, Health and Sport. 2019; 9(11): 277-286.

6. Gozhenko Al, Smagliy SS, Korda IV, Badiuk NS, Zukow W, Popovych IL. Functional relationships between parameters of uric acid exchange and immunity in female rats. Actual problems of transport medicine. 2019; 4 (54): 123-131.

7. Gozhenko Al, Smagliy VS, Korda IV, Badiuk NS, Zukow W, Popovych IL. Features of immune status in different states of uric acid metabolism in female rats. Journal of Education, Health and Sport. 2019; 9(12): 167-180.

8. Gozhenko Al, Smagliy VS, Korda IV, Badiuk NS, Zukow W, Kovbasnyuk MM, Popovych IL. relationships between parameters of uric acid exchange and immunity as well as microbiota in patients with neuroendocrineimmune complex dysfunction. Journal of Education, Health and Sport. 2020; 10(1): 165-175. 
9. Gozhenko Al, Smagliy VS, Korda IV, Badiuk NS, Zukow W, Popovych IL. Functional relationships between parameters of uric acid exchange and immunity in female rats. In: Rehabilitation Medicine and HealthResort Institutions Development. Proceedings of the 19th International Applied Research Conference (Kyïv, 11-12 December 2019). Edited by O. Gozhenko, W. Zukow. Toruc, Kyiv. 2019: 23-24.

10. Ivassivka SV, Popovych IL, Aksentiychuk BI, Flyunt IS. Physiological Activity of Uric Acid and its Role in the Mechanism of Action of Naftussya Water [in Ukrainian]. Kyiv. Computerpress; 2004: 163 p.

11. Khaitov RM, Pinegin BV, Istamov Khl. Ecological Immunology [in Russian]. Moskva: VNIRO; 1995: 219 p.

12. Klecka WR. Discriminant Analysis [trans. from English in Russian] (Seventh Printing, 1986). In: Factor, Discriminant and Cluster Analysis. Moskva Finansy i Statistika; 1989: 78-138.

13. Kul'chyns'kyi AB, Kovbasnyuk MM, Kyjenko VM., Zukow W, Popovych IL. Neuro-immune relationships at patients with chronic pyelonephrite and cholecystite. Communication 2. Correlations between parameters EEG, HRV and Phagocytosis. Journal of Education, Health and Sport. 2016; 6(10): 377-401.

14. Lapovets' LY, Lutsyk BD. Handbook of Laboratory Immunology [in Ukrainian]. Lviv; 2002: 173 p.

15. Perederiy VG, Zemskov AM, Bychkova NG, Zemskov VM. Immune status, principles of its evaluation and correction of immune disorders [in Russian]. Kyiv. Zdorovya; 1995: $211 \mathrm{p}$.

16. Petsyukh SV, Petsyukh MS, Kovbasnyuk MM, Barylyak LG, Zukow W. Relationships between Popovych's Adaptation Index and parameters of ongoiging HRV and EEG in patients with chronic pyelonephrite and cholecystite in remission. Journal of Education, Health and Sport. 2016; 6(2): 99110.

17. Popadynets' OO, Gozhenko Al, Zukow W, Popovych IL. Relationships between the entropies of EEG, HRV, immunocytogram and leukocytogram. Journal of Education, Health and Sport. 2019; 9(5): 651-666.

18. Popovych Al. Features of the immunotropic effects of partial components of the balneotherapeutic complex of spa Truskavets'. Journal of Education, Health and Sport. 2018; 8(12): 919-935.

19. Popovych Al. Features of the neurotropic effects of partial components of the balneotherapeutic complex of spa Truskavets'. Journal of Education, Health and Sport. 2019; 9(1): 396-409.

20. Popovych IL. Information effects of bioactive water Naftyssya in rats: modulation entropic, prevention desynchronizing and limitation of disharmonizing actions water immersion stress for information components of neuroendocrine-immune system and metabolism, which correlates with gastroprotective effect [in Ukrainian]. Medical Hydrology and Rehabilitation. 2007; 5(3): 50-70.

21. Popovych IL, Kul'chyns'kyi AB, Gozhenko Al, Zukow W, Kovbasnyuk MM, Korolyshyn TA Interrelations between changes in parameters of HRV, EEG and phagocytosis at patients with chronic pyelonephritis and cholecystitis. Journal of Education, Health and Sport. 2018; 8(2): 135-156.

22. Shannon CE. Works on the theory of informatics and cybernetics [transl. from English to Russian]. Moskva: Inostrannaya literatura; 1963: 329 p.

23. Struk ZD, Mel'nyk OI, Zukow W, Popovych IL. The diversity of immune reactions to balneotherapy and their accompaniments. Journal of Education, Health and Sport. 2019; 9(11): 349-373.

24. Yushkovs'ka OG. Using information theory to study adaptive responses in the body athletes [in Ukrainian]. Medical Rehabilitation, Kurortology, Physiotherapy. 2001; 1(25): 40-43.

Впервые поступила в редакцию 11.12.2019 г. Рекомендована к печати на заседании редакционной коллегии после рецензирования 